\title{
A decade of improved access to screening is associated with fewer colorectal cancer deaths in African Americans: a single-center retrospective study
}

\author{
Yahuza Siba ${ }^{a}$, Joan Culpepper-Morgan ${ }^{a}$, Menachem Schechtera ${ }^{a}$ Eric Alatevi ${ }^{b}$, Sainabou Jallow ${ }^{b}$, \\ Jude Onaghise ${ }^{b}$, Albert Seyc, Lisa Ozickª, Raja Sabbagh ${ }^{d}$ \\ Harlem Hospital Center, Columbia University Medical Center, New York; Ashtabula County Medical Center, \\ Ohio, USA
}

\begin{abstract}
Background Controversy exists as to whether disparities in colorectal cancer (CRC) outcomes in African Americans (AAs) are best resolved by screening at age 45 or by proper use of existing guidelines. In 2004, an aggressive colonoscopy-based CRC screening program was implemented throughout New York City. Our goal was to determine the effect of that program on CRC outcomes in our mostly AA population.
\end{abstract}

Methods CRC cases entered into Harlem Hospital's tumor registry from January 1992 to December 2011 were divided into two cohorts: 1992-2003, the pre-intensive screening era (PSE), and 2004-2011, the intensive screening era (ISE). Each cohort was reviewed for demographics, indication for colonoscopy, tumor location, tumor stage, and mortality. Multivariate analysis was applied to the pooled cohorts to determine factors associated with survival.

Results Inclusion criteria were met by 379 patients: 207 PSE and 172 ISE. Racial distribution, gender, age at presentation, and tumor location were not different during the two eras. Over 75\% of patients were AA. During the ISE, $84 \%$ were insured compared to $34 \%$ in the PSE $(\mathrm{P}<0.0001)$. Fewer patients died during the ISE $(21 \%)$ than during the PSE $(67 \%)(\mathrm{P}<0.0001)$. The ISE patients were diagnosed with earlier stages of CRC compared to the PSE. Increased survival was associated with being insured (hazard ratio [HR] 1.91, 95\% confidence interval [CI] 1.30-2.81), distal tumors (HR 1.43, 95\%CI 1.05-1.95), and being female (HR 1.36, 95\%CI 1.01-1.850).

Conclusions A multifaceted program reduced CRC outcome disparities in a poor AA community. Aggressive implementation of current colonoscopy screening guidelines still has unrealized potential to reduce CRC mortality disparities in AAs.

Keywords Colorectal cancer, screening, colorectal cancer deaths, African Americans

Ann Gastroenterol 2017; 30 (4): 1-8

Departments of ${ }^{a}$ Medicine, Division of Gastroenterology, Harlem Hospital Center, Columbia University Medical Center, New York (Yahuza Siba, Joan Culpepper-Morgan, Menachem Schechter, Lisa Ozick); ${ }^{b}$ Medicine, Harlem Hospital Center, Columbia University Medical Center, New York (Eric Alatevi, Sainabou Jallow, Jude Onaghise); ${ }^{c}$ Hospitalist Medicine, Ashtabula County Medical Center, Ohio (Albert Sey); dSurgery, Harlem Hospital Center, Columbia University Medical Center, New York (Raja Sabbagh), USA

Conflict of Interest: None

Correspondence to: Yahuza Siba, MD, Department of Medicine, Division of Gastroenterology, Harlem Hospital Center, Columbia University Medical Center, 506 Lenox Avenue, MLK 13-106, NY, NY 10037, USA, e-mail: yahu294@gmail.com

Received 16 February 2017; accepted 27 March 2017; published online 12 May 2017

DOI: https://doi.org/10.20524/aog.2017.0155

\section{Introduction}

In the United States (US), colorectal cancer (CRC) is the third most common cause of cancer and the second leading cause of cancer deaths [1]. Nationally, the incidence rate of CRC has declined since the 1970s. The decline in women and men is $2.3 \%$ per year and $3.0 \%$ per year, respectively. This decline is mainly due to the detection and removal of premalignant adenomas through CRC screening. The decline has occurred among every major racial group, the only exception being American Indian and Native Alaskan women [2-4].

Although great progress has been made in the last 4 decades in reducing the incidence and mortality of CRC nationwide, the improvement for African Americans (AAs) has not been as great as for white Americans (Table 1). There are several theories to explain these racial disparities. The first 
Table 1 Change in the incidence of colorectal cancer (CRC) and mortality by race and sex: $1975-2011$ per 100,000 population (age adjusted to the year 2000 standard United States Population)

Incidence of CRC for US adult blacks and white males and females

\begin{tabular}{ccccc}
\hline Year & $\begin{array}{c}\text { Black } \\
\text { males }\end{array}$ & $\begin{array}{c}\text { Black } \\
\text { females }\end{array}$ & $\begin{array}{c}\text { White } \\
\text { males }\end{array}$ & $\begin{array}{c}\text { White } \\
\text { females }\end{array}$ \\
\hline 1975 & 59.33 & 54.66 & 69.75 & 54.05 \\
2011 & 54.34 & 41.49 & 43.33 & 33.72 \\
\hline
\end{tabular}

Mortality of CRC for US adult blacks and white males and females

\begin{tabular}{ccccc}
\hline Year & $\begin{array}{c}\text { Black } \\
\text { males }\end{array}$ & $\begin{array}{c}\text { Black } \\
\text { females }\end{array}$ & $\begin{array}{c}\text { White } \\
\text { males }\end{array}$ & $\begin{array}{c}\text { White } \\
\text { females }\end{array}$ \\
\hline 1975 & 30.09 & 24.55 & 32.24 & 25.06 \\
2011 & 26.20 & 17.71 & 17.05 & 12.32 \\
\hline
\end{tabular}

focuses on the socioeconomic barriers to CRC screening, including insurance, physician availability, access to and utilization of CRC screening. A second theory is based on different tumor biology, including more right-sided cancers and earlier presentation among AAs [5-7]. Because of these arguments, in 2005 the American College of Gastroenterology recommended lowering the screening age for AAs from 50 to 45 years. However, not all societies have agreed with this recommendation $[8,9]$.

Harlem Hospital Center, located in northern Manhattan, NY, is a safety-net hospital. According to the 2000 US census, central Harlem has a population of 151,113 : $67 \%$ are AA (compared to $12 \%$ nationally), 20\% Hispanic Americans (13\% US average), $8 \%$ white (75\% US average), $19 \%$ of whom are foreign-born (12\% US average), and 3\% Asian Americans (4\% US average). It is one of the poorest neighborhoods in all of New York City (NYC), with a median household income $50 \%$ below the US average. One third live below the official poverty line. Only $66 \%$ have graduated from high school compared to $80 \%$ nationally [10].

A prior cohort study by Freeman et al, which evaluated CRC cases presenting between 1973 and 1992, also using tumor registry records, demonstrated a higher mortality rate and lower 5-year survival compared to national SEER (Surveillance, Epidemiology, and End Results) database rates for whites and blacks. This was attributed to late disease presentation due to the multiple effects of poverty, including poor education and a lack of access to preventive care [11].

In 2003 an aggressive CRC screening program was implemented throughout NYC (The Citywide Colon Cancer Control Coalition: C5). Essential components of this campaign included community outreach and advocacy, expansion of the endoscopy capacity of NYC Health and Hospital Corporations (NYCHHC) hospitals, media campaigns focused on poor neighborhoods and populations with low screening rates, collaboration with and direct referrals from primary care providers, the use of hospital-based culturally sensitive patient navigators who linked referred patients to colonoscopy screening, and grants from the American Cancer Society to cover some uninsured patients [12]. Our aim was to determine the effect of the C5 program on CRC outcomes in our mostly AA population.

\section{Patients and methods}

This was a single-center, retrospective cohort analysis of CRC cases reported to the Harlem Hospital Center's Tumor Registry between January 1, 1992 and December 31, 2011. Archived pathology reports over the same period were also reviewed to cross check for missing data and duplication. Patients with adenomas without frank carcinoma, carcinoid tumors, colorectal lymphomas, secondary metastases to the colon and rectum, familial cancer syndromes-e.g. familial adenomatous polyposis or hereditary non-polyposis colorectal cancer-and patients diagnosed elsewhere were excluded. Also excluded were patients aged over 89 years, patients who were not followed up following initial biopsy-proven CRC, and patients who did not have a complete data set of the study variables of interest. A total of 448 patients were selected for chart abstraction after removal of duplicates. Based on the criteria mentioned above, 69 patients were excluded (Fig. 1). The study was approved by the Biomedical Research Alliance of NYC's Institutional Review Board as exempt.

The patients were divided into 2 cohorts: 1992-2003, the pre-intensive screening era (PSE), and 2004-2011, the intensive screening era (ISE). Demographic variables were recorded for each patient and compared for each cohort. These included: age at diagnosis, sex, and race/ethnicity. Death during the decade of evaluation was the primary endpoint. Secondary endpoints included insurance status, method of diagnosis (screening vs. diagnostic colonoscopy), and anatomical site of tumor. Treatments given to patients, including surgery, radiation and chemotherapy, were also recorded and compared between the 2 cohorts. The effect of demographic characteristics on overall survival was examined using pooled cohort data.

\section{Statistical analysis}

Statistical analysis was performed using $\mathrm{R}$, a programming language and software environment for statistical computing and visualizing data ( $\mathrm{R}$ software package version 3.1.1), and Microsoft Excel [13]. Categorical data sets were analyzed with the Pearson chi-square test. With a $95 \%$ confidence interval (CI), a 2-tailed P-value of $<0.05$ was considered statistically significant for all analyses. Results of the multivariate analysis are shown as hazard ratio (HR). Clinical survival times were obtained using the actuarial life-table method [14]. To adjust the survival rates for deaths from causes other than CRC, and to allow for comparison of our rates with other databases, we calculated relative survival rates (RSR), as the ratio of the observed survival rate (OSR) to the expected survival 


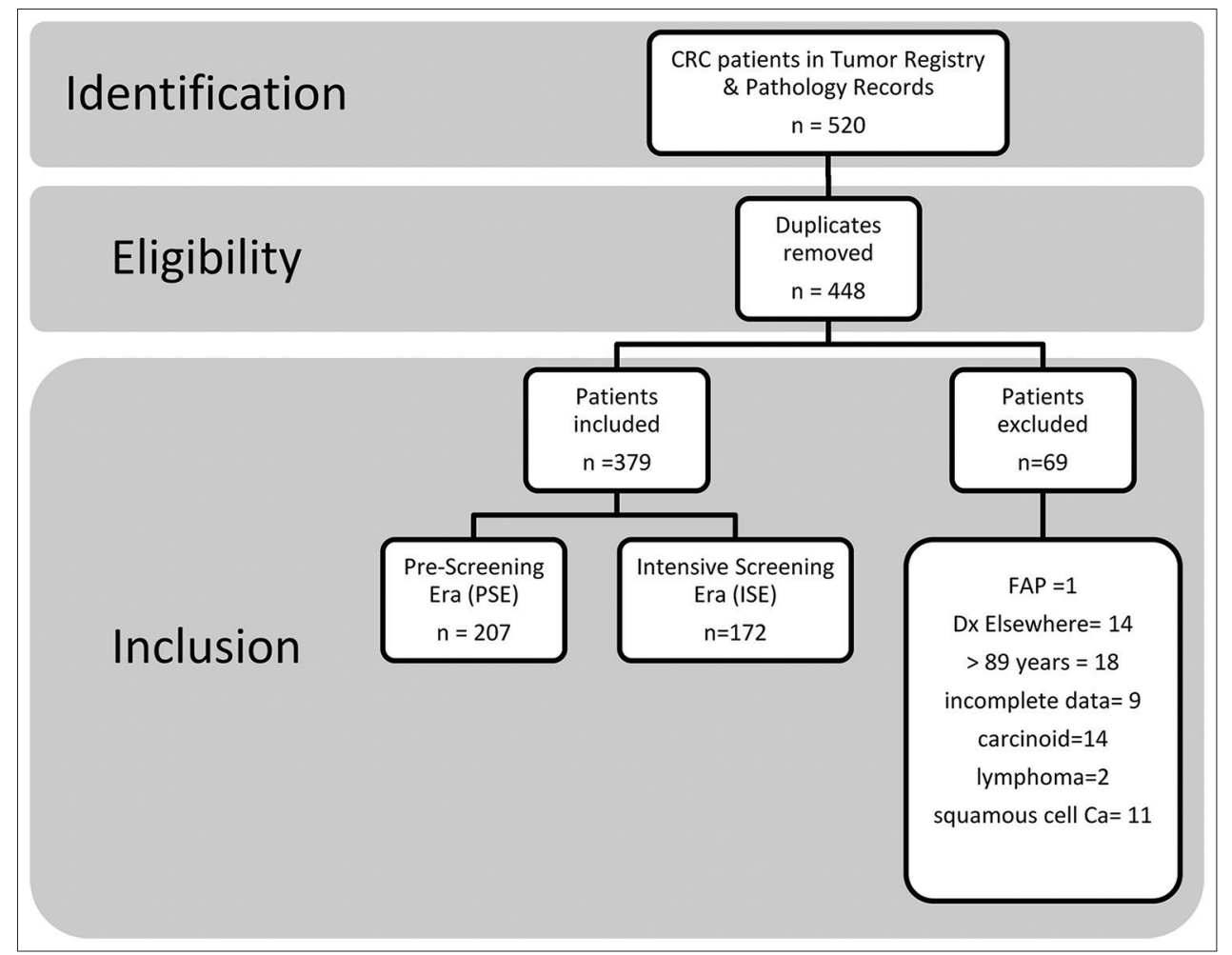

Figure 1 Flowchart of study participants

CRC, colorectal cancer; FAP, familial adenomatous polyposis

Table 2 Baseline demographics of our study cohort during the pre-intensive and intensive screening eras

\begin{tabular}{lccc}
\hline Characteristic & $1992-2003$ & $2004-2011$ & P-value \\
\hline Male & $100(48 \%)$ & $86(50 \%)$ & 0.27 \\
$\begin{array}{l}\text { Average age at } \\
\text { diagnosis (years) }\end{array}$ & 64.1 & 65.5 & 6.29 \\
Race & & & \\
$\quad$ Black & $155(75 \%)$ & $131(76 \%)$ & 0.19 \\
Hispanic & $39(18 \%)$ & $35(20 \%)$ & 1.07 \\
$\quad$ Other & $13(6 \%)$ & $6(4 \%)$ & 0.11 \\
Insurance & $70(34 \%)$ & $145(84 \%)$ & $<0.0001$ \\
Proximal tumors & $72(35 \%)$ & $74(43 \%)$ & 4.75 \\
Screening & $11(5.3 \%)$ & $31(18 \%)$ & 0.0019 \\
Deaths & $139(67 \%)$ & $37(21 \%)$ & $<0.0001$ \\
\hline
\end{tabular}

Data are given as $\mathrm{n}(\%)$ unless otherwise stated

rate (ESR) [15]. The OSRs were calculated by the life-table method, and the ESR was obtained for a group of people in the general population in the State of New York, similar with respect to age, sex, and race, during the same period of time. The standard error (SE) of the OSR was computed from Greenwood's formula and the SE of the RSR was computed as the SE of OER/ESR. Time-to-event data were summarized with a Kaplan-Meier survival analysis and compared using log rank tests [16].

\section{Results}

Inclusion criteria were met by 379 patients for the period under study. Of these, 207 were diagnosed during the PSE and 172 during the ISE. The median age of the study participants was 65 years (interquartile range 54-74) and 53\% were female. Two hundred eighty-six patients (75\%) were AA, 74 (20\%) were Hispanic and 19 (5\%) were from other racial groups (Table 2). During the PSE, $64 \%$ of the CRC diagnosed were proximal in location (i.e. from the cecum to the sigmoid flexure), compared to $67 \%$ during the ISE. The racial distribution, sex, age at presentation, and proximal tumor distribution were did not differ significantly between the 2 cohorts.

More patients had insurance coverage during the ISE (141, 84\%) than the PSE $(61,34 \%)$. This difference was highly statistically significant $(\mathrm{P}<0.0001)$. Only $5.3 \%(\mathrm{n}=11)$ of CRC patients were diagnosed with screening as opposed to diagnostic colonoscopy during the PSE. That number tripled in the ISE to $18 \%(n=31)$ (Table 2). Patients in the PSE presented at a much later stage of CRC than patients in the ISE. During the PSE, 6 patients (3\%) had stage 0 disease, $6(3 \%)$ were stage I, 37 (18\%) were stage II, 63 (30\%) were stage III, with $56(27 \%)$ stage IV and 39 (19\%) unstaged disease. During the ISE, 47 (27\%) had stage 0 disease, $21(12 \%)$ were stage I, 55 (32\%) were stage II, 35 (20\%) were stage III, with 8 (5\%) stage IV and 7 (4\%) unstaged disease (Fig. 2). In the PSE, $67 \%$ of the CRC patients died $(n=139)$, in contrast to only $21 \%$ of the CRC patients in the ISE $(n=37)(\mathrm{P}<0.0001)$. 


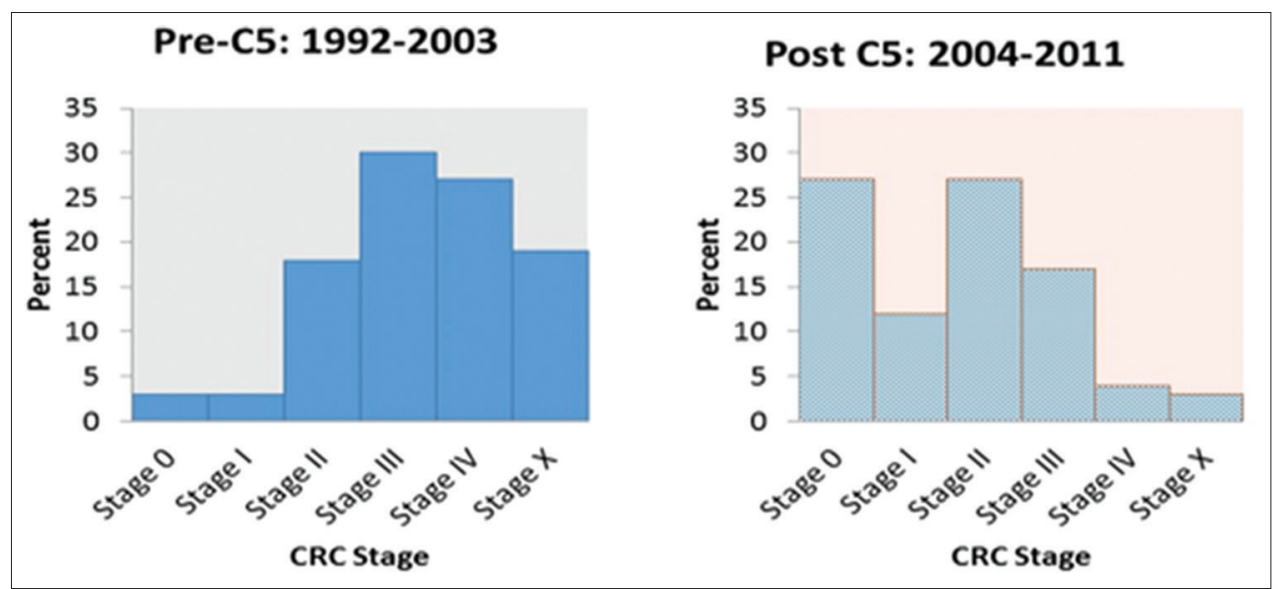

Figure 2 Distribution of American Joint Committee on Cancer stages of colorectal cancer (CRC), comparing the pre-intensive (pre-C5) and intensive (Post C5) screening eras

During the PSE, 175 patients (85\%) underwent surgery and 4 (2\%) had colonoscopic polypectomy for carcinoma in situ. Of the 175 surgical interventions, $112(63 \%)$ were performed with the intention to cure. Of those patients, 49 (41\%) had stages I or II and 63 (59\%) had stage III disease. Palliative surgery for symptom relief was provided to 63 patients. Of the 39 unstaged patients, 28 received no treatment, because they either refused treatment $14(6 \%)$, were unfit for treatment due to medical reasons $9(5 \%)$, or were lost to follow up $5(2 \%)$. The remaining 11 (5\%) sought a second opinion elsewhere for their staging evaluation. One hundred sixteen patients (56\%) received chemotherapy: adjuvant chemotherapy was given to $16(14 \%)$ patients with stage II disease and 63 (54\%) patients with stage III disease, while palliative chemotherapy was offered to 37 (32\%). Twelve (6\%) patients had adjuvant radiotherapy. Eighteen patients (9\%) received both chemotherapy and radiotherapy. Thirteen patients had recurrent disease during 5 years of follow up: 3 received surgical treatment, 5 had adjuvant chemotherapy, 2 had adjuvant radiotherapy, and 3 had adjuvant chemotherapy and radiotherapy.

During the ISE, 157 (91\%) patients underwent surgery, 145 with the intention of potential cure. Twelve (7\%) had colonoscopic polypectomies for stage 0 disease, 111 (68\%) had surgery for stage I or II disease and 34 (21\%) for stage III disease, and $12(7 \%)$ had palliative surgery. Three patients did not have any treatment because of medical reasons. Chemotherapy was given to 88 (51\%) patients, of whom 39 with stage II disease, 34 with stage III disease and 7 with unstaged disease had adjuvant chemotherapy, while palliative chemotherapy was given to 8 patients. Seven patients had adjuvant radiotherapy. Adjuvant chemotherapy and radiotherapy was given to 11 patients. Six patients had recurrent disease during 5 years of follow up. For treatment of recurrence, 4 had adjuvant chemotherapy and 2 had adjuvant radiotherapy (Table 3 ).

The 2 cohorts were pooled to calculate survival data and to evaluate risk factors known to affect survival in this study population. Males were less likely to survive than females
Table 3 Treatment received during the pre-intensive (PSE) and intensive (ISE) screening eras

\begin{tabular}{lccc}
\hline Treatment & $\begin{array}{c}\text { PSE } \\
(\mathrm{n}=207)\end{array}$ & $\begin{array}{c}\text { ISE } \\
(\mathrm{n}=172)\end{array}$ & P-value \\
\hline Surgery & $175(85 \%)$ & $157(91 \%)$ & $\mathrm{NS}$ \\
Polypectomy & $4(2 \%)$ & $12(7 \%)$ & $<0.003$ \\
Intention to cure & $112(63 \%)$ & $145(84 \%)$ & $<0.005$ \\
Adjuvant therapies: & & & \\
Chemotherapy & $116(56 \%)$ & $88(51 \%)$ & $\mathrm{NS}$ \\
Radiotherapy & $12(5 \%)$ & $7(4 \%)$ & $\mathrm{NS}$ \\
Chemoradiation & $18(9 \%)$ & $11(6 \%)$ & $\mathrm{NS}$ \\
\hline
\end{tabular}

(hazard ratio $[\mathrm{HR}] 1.36,95 \% \mathrm{CI} 1-1.85, \log \operatorname{rank} \mathrm{P}=0.05$; Fig. 3A). Patients with proximal tumors had worse survival compared to those with distal tumors (HR 1.43, 95\%CI 1.0481.948 , log rank $\mathrm{P}=0.023$; Fig. $3 \mathrm{~B}$ ). Overall survival in noninsured patients was poor compared to patients who had insurance (HR 1.91, 95\%CI 1.30-2.81, log rank $\mathrm{P}=0.0008$; Fig. $3 \mathrm{C}$ ). There was no statistically significant difference when survival was compared for age above or below 65 years (HR 1.39, 95\%CI 0.96-1.78, log rank $\mathrm{P}=0.895$ ).

Survival among patients in Harlem continues to lag behind US blacks and US whites when compared to the SEER database (Fig. 4) [17]. There was a modest increase in survival from an average of $20 \%$ in the PSE to $38 \%$ in the last 4 years of the ISE. However, there was a statistically significant difference in overall survival between SEER database patients and Harlem patients $(\mathrm{P}<0.05)$.

\section{Discussion}

In this hospital-based cohort study of mainly AAs, we confirmed the earlier age of CRC diagnosis in AAs compared to whites nationally. The mean age of the pooled cohorts at 


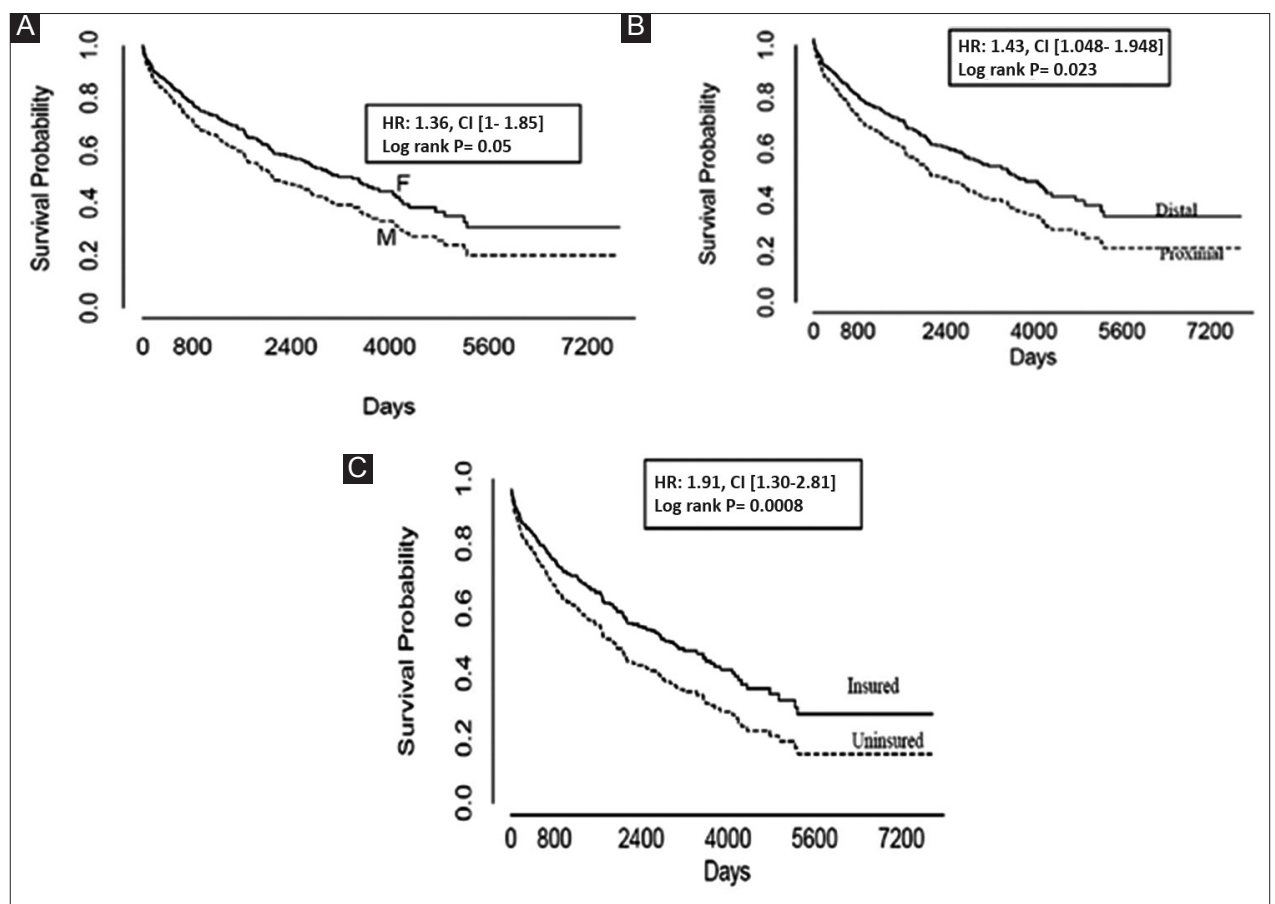

Figure 3 Kaplan-Meier survival curves comparing (A) males (M) vs. females (F), (B) proximal vs. distal tumors, and (C) insured vs. uninsured patients $H R$, hazard ratio; CI, confidence interval

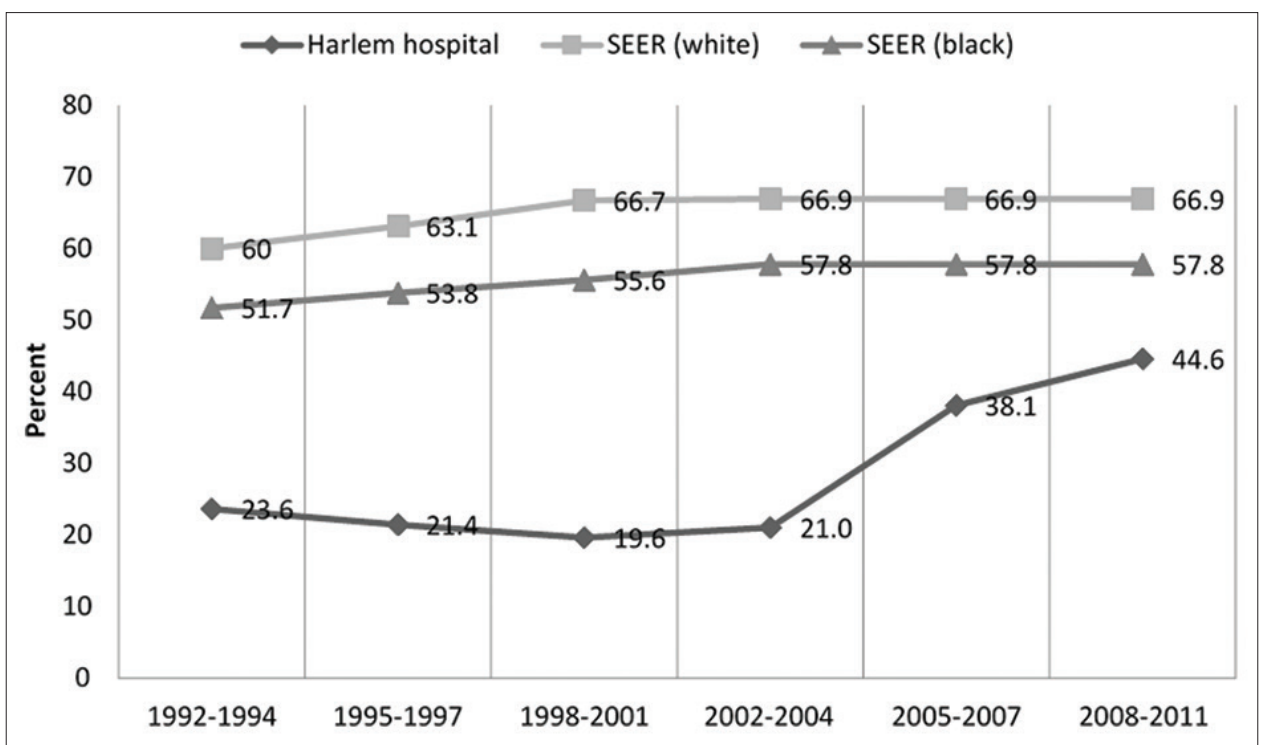

Figure 4 Five-year survival for colorectal cancer, comparing Harlem, SEER (blacks) and SEER (whites)

SEER, surveillance, epidemiology, and end results database

diagnosis was 64.8 years. Karami et al reported the median age of diagnosis of AAs to be 67 years compared to 73 years for whites [18]. Furthermore, during the intensive screening era, more patients had insurance at the time of diagnosis and more patients were diagnosed by screening colonoscopy than from diagnostic colonoscopy. In addition, colon cancers were diagnosed at an earlier and more treatable stage. Most importantly, fewer patients died of their cancer.
Our cohort was $75 \%$ AA. This did not change significantly between the study decades. We confirmed previously reported differences in AAs versus Caucasians. CRC presented at an earlier age in our patients. The percentage of right-sided cancer, which is reported to be more prevalent in AAs, was not statistically significantly different between our 2 cohorts, being $35 \%$ and $43 \%$, respectively (Table 2 ). We also confirmed, using pooled cohort data, the poor survival of males, as well as those with right-sided 
cancers (Fig. 3A, B). Other biologic factors, such as multiple coexisting morbidities and possibly more aggressive tumor biology, have been cited as reasons why AAs lag behind other races in CRC survival [19-21]. Some studies have shown that race as a factor disappears when treatment is equal among study groups. However, AAs are less likely compared to whites to receive the most appropriate surgery and adjuvant chemoradiotherapy, even though AA patients appear to suffer fewer adverse effects of chemotherapy compared to whites [22-24].

The improvement in the proportion of patients in the second decade who had health insurance was quite remarkable, improving from $34 \%$ of the cohort to $84 \%$. The increase in insurance coverage between the 2 cohorts probably reflects the successful aggressive efforts by the state of NY to educate and enroll vulnerable adults into managed Medicaid programs [25-27]. Most of the patients served by the municipal safety-net system, of which Harlem Hospital is a part, are insured by Medicaid. State mandated Medicaid Managed Care enrollment was approved by the federal government in 1997 [28]. In 2003 alone, 1 million new beneficiaries were enrolled in NYC [27]. From 2000-2012 enrollment is estimated to have grown by $80 \%$ statewide, covering about 5 million New Yorkers. Most of the statewide expansion, from 2000-2008, occurred in NYC [28]. A 2011 study of the C5 Program also reported that a lack of insurance was associated with lower probability of having a colonoscopy (relative risk 0.61, 95\%CI 0.51-0.73, P<0.001) [12].

Furthermore, during the ISE, the American Cancer Society collaborated with the NYC DOHMH and HHC hospitals to provide lifesaving colonoscopies to uninsured New Yorkers. These efforts, generously funded through a NYC Council grant, supported the increase in the city's overall cancer screening rate from $42 \%$ to $64 \%$ from 2003 to 2012 [29]. However, there are still an estimated 116,000 uninsured New Yorkers over the age of 50 who have never undergone a colonoscopy [12].

In a nationally representative study by $\mathrm{Du}$ et al, looking at the impact of racial disparities and socioeconomic status on CRC survival, 70\% of AA patients fell into the poorest quartiles of socioeconomic status, compared to $21 \%$ of Caucasians. There was a $19 \%$ increase in all-cause mortality among patients who lived in communities with the lowest socioeconomic status, compared to patients who lived in communities with the highest socioeconomic status (HR 1.19, 95\%CI 1.13-1.26). The risk of dying was reduced only marginally after controlling for age [30]. Another study that analyzed the association between insurance and cancer outcomes revealed the existence of survival disparities, even within the same race [31]. Our study also revealed an overall survival advantage among those with medical insurance compared to those without insurance (Fig. 3C). In general, uninsured patients have worse outcomes throughout the continuum of cancer care: from primordial prevention of modifiable cancer risk factors, to early detection through screening, to treatment, survival, and even comfort care. In addition, contact with the healthcare system provides avenues for discussion of health, promoting behaviors such as exercise, nutrition/dietary counseling, tobacco cessation, weight-loss programs, and management of chronic medical conditions. Individuals without insurance are less likely to report an encounter with a provider, they are also less likely to have received any screening for CRC, breast and cervical cancers [32-37].

While this study was not designed to distinguish the effects of patient navigation versus increased insurance on the ultimate outcome of mortality, it is worth noting that other studies have shown that patient navigation is essential to ensure that vulnerable populations with abnormal screening results are properly linked to care [38]. Patient navigation is a technique that was developed at Harlem Hospital in 1990 by Dr. Harold Freeman as a way to improve breast cancer outcomes in poor black women [39]. From outreach through detection and treatment resolution, the navigators increase patients' awareness of available services, work through financial barriers, and facilitate access to care. The navigators help patients overcome scheduling conflicts, social support deficits, legal concerns, transportation issues and more. Although 50\% of Freeman's original cohort was uninsured, 5-year survival still improved from $39 \%$ to $70 \%$ [40]. Patient navigation was and is a key component of the C5 coalition effort. We suspect that navigation played a very important role in ensuring that those patients with cancer who were identified by either diagnostic or screening colonoscopy were effectively linked to the proper treatment.

The increased diagnosis of CRC in our cohort at an asymptomatic stage is concordant with the trend for the rest of the US $[1,22]$. Nationally, CRC screening rates have increased from $19 \%$ in 2000 to $59 \%$ in 2010 to $65 \%$ in 2012 [41]. Recent reports using micro-simulation modeling have shown that screening is the intervention with the greatest impact on the decline in CRC incidence and mortality rates, with minor contributions from risk factor reduction and improved treatment $[5,22]$. Another micro-simulation model by Yang et al, using 30 years of SEER data and looking at the impact of screening on the US population, reported that approximately 250,000 to 500,000 CRC cases were averted during the period of 1987 to 2010 [42]. A systematic review and meta-analysis of the effect of screening colonoscopy and sigmoidoscopy on CRC incidence and mortality suggests a $40-60 \%$ lower risk of incident CRC and death for proximal cancers [43]. We posit a similar rate of declining CRC incidence and mortality for AA patients with higher utilization of screening.

Even though the rate of tumors diagnosed by screening colonoscopy tripled in comparison with diagnostic colonoscopy, the overall rate was still modest (18\%). Nevertheless, significantly more cancers were diagnosed at an earlier, more treatable stage in the ISE decade (Fig. 2). It is likely that fewer patients died in the ISE group because their cancers were diagnosed at an earlier stage. A review of treatments given indicates that more patients were more amenable to curative treatment (Table 3). During the ISE, there were more surgeries with the intention of cure than there were in the PSE group $(\mathrm{P}<0.005)$. In addition, more polypectomies were performed for stage 0 lesions in the ISE $(\mathrm{P}<0.003)$ and fewer patients were given only palliative treatment. Many stage II patients received adjuvant chemotherapy in our cohort: care was taken to recommend treatment for patients with inadequately sampled nodes, patients who presented with obstruction or perforation, 
patients with T3-T4 lesions or indeterminate margins, and tumors with poorly differentiated histology; last but not least, provider recommendations may also have been a factor. This finding is similar to a recent report by Manjelievskaia et al that found overuse of adjuvant chemotherapy in young patients with CRC across all stages, without increased survival advantage [44]. Further research to evaluate appropriate use of chemotherapy in stage II CRC is warranted.

It is important to note that, despite the decade of improvement in screening and mortality, the 5-year survival in our cohort is still lower and continues to lag behind SEER data for whites and blacks [17]. As our study revealed, the current intensive screening decade was associated with one third as many deaths as the previous decade.

Our study has the following important public health implications. First, we demonstrated that the expansion of insurance within the state of NY provided increased access to and utilization of colonoscopy. Second, with increased access to and utilization of colonoscopic screening, the survival from CRC in this socioeconomically disadvantaged black community increased and followed the national trend. Lastly, we conclude that further improvements in access to care, specifically improved insurance coverage, could result in even more lives saved.

This cross-sectional single-center study has several limitations. Our study did not directly measure the rate of screening in our population; we only compared screening colonoscopy to diagnostic colonoscopy for CRC diagnosis. Secondly, we could not evaluate the impact of other factors that are more difficult to measure, such as level of patient education and physician advocacy, between the 2 cohorts. Aggressive educational programs aimed at primary care providers and patients could have resulted in increased awareness and referral for screening colonoscopy. Furthermore, increased insurance may have allowed minimally symptomatic patients to come to the attention of a healthcare provider early enough for them to be referred for evaluation and treatment. Finally, comparing a hospital-based registry to the population-based SEER cancer registry may not be ideal, since some SEER patients may be diagnosed outside the hospital setting and may not ever go to the hospital.

In conclusion, despite not addressing all disparity issues, the C5 program made significant progress in reducing CRC mortality disparity in our poor mostly AA population. We observed a major shift in the stage of cancer diagnosis afforded by increased access to preventive care. More studies designed to evaluate the impact of facilitating equitable access to CRC screening in socioeconomically disadvantaged black communities are warranted. Our data suggest that the full effect of implementing current screening guidelines in this population have not yet been realized.

\section{Acknowledgments}

We acknowledge the excellent assistance of the Harlem Tumor Registry, particularly Ms. Marjorie Sneed and her colleagues, who provided us the CRC data. Furthermore, we thank Mr. Steve Scopa of SEER-Stat Technical support, who addressed our questions during the collection and synthesis of our data.

\section{Summary Box}

\section{What is already known:}

- Disparities in the incidence of colorectal cancer (CRC) and mortality exist between African Americans (AAs) and whites

- CRC in AAs presents at an earlier age, a later stage, and has a more proximal location compared to whites

- It is unclear whether the above disparities are best resolved by screening AAs at an earlier age or by aggressive implementation of current guidelines

\section{What the new findings are:}

- The New York City Citywide Colon Cancer Control Coalition (C5) implemented a multifaceted program that increased access to health insurance and screening colonoscopy

- During the decade of the C5 program, CRC was diagnosed at an earlier stage and deaths from CRC were reduced by two thirds in the AA community served by Harlem Hospital

- Early screening of AAs may not be needed, as aggressive implementation of current screening guidelines may still be able to reduce racial disparities in CRC outcomes

\section{References}

1. Siegel RL, Miller KD, Jemal A. Cancer Statistics, 2017. CA Cancer J Clin 2017;67:7-30.

2. Levine JS, Ahnen DJ. Clinical practice. Adenomatous polyps of the colon. N Engl J Med 2006;355:2551-2557.

3. U.S. Preventive Services Task Force. Screening for colorectal cancer: U.S. Preventive Services Task Force recommendation statement. Ann Intern Med 2008;149:627-637.

4. Edwards BK, Ward E, Kohler BA, et al. Annual report to the nation on the status of cancer, 1975-2006, featuring colorectal cancer trends and impact of interventions (risk factors, screening, and treatment) to reduce future rates. Cancer 2010;116:544-573.

5. Liss DT, Baker DW. Understanding current racial/ethnic disparities in colorectal cancer screening in the United States: the contribution of socioeconomic status and access to care. Am J Prev Med 2014;46:228-236.

6. Ollberding NJ, Nomura AM, Wilkens LR, Henderson BE, Kolonel LN. Racial/ethnic differences in colorectal cancer risk: the multiethnic cohort study. Int J Cancer 2011;129:1899-1906.

7. Irby K, Anderson WF, Henson DE, Devesa SS. Emerging and widening colorectal carcinoma disparities between Blacks and 
Whites in the United States (1975-2002). Cancer Epidemiol Biomarkers Prev 2006;15:792-797.

8. Agrawal S, Bhupinderjit A, Bhutani MS, et al; Committee of Minority Affairs and Cultural Diversity, American College of Gastroenterology. Colorectal cancer in African Americans. Am J Gastroenterol 2005; 100:515-523; discussion 514.

9. Levin B, Lieberman DA, McFarland B, et al; American College of Radiology Colon Cancer Committee. Screening and surveillance for the early detection of colorectal cancer and adenomatous polyps, 2008: a joint guideline from the American Cancer Society, the US Multi-Society Task Force on Colorectal Cancer, and the American College of Radiology. Gastroenterology 2008;134:1570-1595.

10. U.S. Census 2000 Available from: http://www.census.gov/main/ www/cen2000.html.

11. Freeman HP, Alshafie TA. Colorectal carcinoma in poor blacks. Cancer 2002;94:2327-2332.

12. Richards CA, Kerker BD, Thorpe L, et al. Increased screening colonoscopy rates and reduced racial disparities in the New York Citywide campaign: an urban model. Am J Gastroenterol 2011;106:1880-1886.

13. Team RDC. R: A language and environment for statistical computing 2007 Available from: http://www.r-project.org.

14. Collet D. Modelling Survival Data in Medical Research. Second ed. New York: Chapman and Hall CRC; 2003.

15. Ederer F, Axtell LM, Cutler SJ. The relative survival rate: a statistical methodology. Natl Cancer Inst Monogr 1961;6:101-121.

16. Greenwood M. The errors of sampling of the survivorship tables. Reports on public health and medical subjects. London: Her Majesty's Staff Office; 1926.

17. Howlader N, Noone AM, Krapcho M, et al. SEER Cancer Statistics Review 1975-2012.

18. Karami S, Young HA, Henson DE. Earlier age at diagnosis: another dimension in cancer disparity? Cancer Detect Prev 2007;31:29-34.

19. Dominitz JA, Samsa GP, Landsman P, Provenzale D. Race, treatment, and survival among colorectal carcinoma patients in an equal-access medical system. Cancer 1998;82:2312-2320.

20. Gornick ME, Eggers PW, Riley GF. Associations of race, education, and patterns of preventive service use with stage of cancer at time of diagnosis. Health Serv Res 2004;39:1403-1427.

21. McMahon LF Jr, Wolfe RA, Huang S, Tedeschi P, Manning W Jr, Edlund MJ. Racial and gender variation in use of diagnostic colonic procedures in the Michigan Medicare population. Med Care 1999;37:712-717.

22. Jemal A, Clegg LX, Ward E, et al. Annual report to the nation on the status of cancer, 1975-2001, with a special feature regarding survival. Cancer 2004;101:3-27.

23. Hodgson DC, Fuchs CS, Ayanian JZ. Impact of patient and provider characteristics on the treatment and outcomes of colorectal cancer. J Natl Cancer Inst 2001;93:501-515.

24. McCollum AD, Catalano PJ, Haller DG, et al. Outcomes and toxicity in african-american and caucasian patients in a randomized adjuvant chemotherapy trial for colon cancer. J Natl Cancer Inst 2002;94:1160-1167.

25. Sandman DR. Health care in New York City: Understanding and shaping change. The Commonwealth Fund [Internet]. 1999 September 1999: [2-8 pp.]. Available from: http://www. cmwf.org.

26. Fiorentini C. Growth in New York's Medicaid enrollment and costs: While enrollment highest in the City, recent increases mostly in the suburbs and upstate. New York City: New York City Independent
Budget Office; 2013.

27. Haslanger K. Medicaid Managed Care in New York: a work in progress. U.S.A.: United Hospital Fund; 2003.

28. Growth in New York's Medicaid enrollment and costs: While enrollment highest in the City, recent increases mostly in the suburbs and upstate. In: New, editor. New York City: IBO; 2013. p. 1-13.

29. Itzkowitz SH, Winawer SJ, Krauskopf M, et al. New York Citywide Colon Cancer Control Coalition: A public health effort to increase colon cancer screening and address health disparities. Cancer 2016;122:269-277.

30. Du XL, Fang S, Vernon SW, et al. Racial disparities and socioeconomic status in association with survival in a large population-based cohort of elderly patients with colon cancer. Cancer 2007;110:660-669.

31. Ward E, Halpern M, Schrag N, et al. Association of insurance with cancer care utilization and outcomes. CA Cancer J Clin 2008;58:9-31.

32. Ioannou GN, Chapko MK, Dominitz JA. Predictors of colorectal cancer screening participation in the United States. Am J Gastroenterol 2003;98:2082-2091.

33. Cokkinides VE, Ward E, Jemal A, Thun MJ. Under-use of smokingcessation treatments: results from the National Health Interview Survey, 2000. Am J Prev Med 2005;28:119-122.

34. Sambamoorthi U, McAlpine DD. Racial, ethnic, socioeconomic, and access disparities in the use of preventive services among women. Prev Med 2003;37:475-484.

35. Coughlin SS, Uhler RJ, Bobo JK, Caplan L. Breast cancer screening practices among women in the United States, 2000. Cancer Causes Control 2004;15:159-170.

36. Patel K, Hargreaves M, Liu J, et al. Factors influencing colorectal cancer screening in low-income African Americans in Tennessee. J Community Health 2012;37:673-679.

37. Haller DG, Catalano PJ, Macdonald JS, et al. Phase III study of fluorouracil, leucovorin, and levamisole in high-risk stage II and III colon cancer: final report of Intergroup 0089. J Clin Oncol 2005;23:8671-8678.

38. Freeman HP. Patient navigation as a targeted intervention: For patients at high risk for delays in cancer care. Cancer 2015;121:3930-3932.

39. Oluwole SF, Ali AO, Adu A, et al. Impact of a cancer screening program on breast cancer stage at diagnosis in a medically underserved urban community. J Am Coll Surg 2003;196:180-188.

40. Freeman HP, Rodriguez RL. History and principles of patient navigation. Cancer 2011;117:3539-3542.

41. Centers for Disease Control and Prevention (CDC). Cancer screening - United States, 2010. MMWR Morb Mortal Wkly Rep 2012;61:41-45

42. Yang DX, Gross CP, Soulos PR, Yu JB. Estimating the magnitude of colorectal cancers prevented during the era of screening: 1976 to 2009. Cancer 2014;120:2893-2901.

43. Brenner H, Stock C, Hoffmeister M. Effect of screening sigmoidoscopy and screening colonoscopy on colorectal cancer incidence and mortality: systematic review and meta-analysis of randomised controlled trials and observational studies. BMJ 2014;348:g2467.

44. Manjelievskaia J, Brown D, McGlynn KA, Anderson W, Shriver CD, Zhu K. Chemotherapy use and survival among young and middleaged patients with colon cancer. JAMA Surg 2017 Jan 25. doi: 10.1001/jamasurg.2016.5050 [Epub ahead of print] 